\title{
WOMEN, MINING AND THE LAW
}

\section{Introduction}

At a recent colloquium of the University of Cape Town's Mineral Law in Africa's initiative ${ }^{1}$ the position of gender and mining were discussed. The discussion raised many issues pertaining to women's position in relation to mining in Africa.

Tapiero ("Women Mine the Risks Men the Benefits" 20102 Inside Mining 12-15) states that "worldwide between 80 and 100 million people are directly and indirectly dependent on non-industrial forms of mining for their livelihoods. Of these, an estimated $30 \%$ are women." The same author then indicates that mining carries risks for women as mining may result in a poor distribution of the mining benefits between men and women; it may lead to social disruption, including matters such as domestic violence, loss of agricultural land and environmental damage and pollution. When decisions are made with regard to mining projects, women are not always consulted and they do not have, due to cultural or religious reasons, a say in decisionmaking, either with regard to employment, or the placing of a mine. There may also be other legal or cultural constraints impacting on the effects that mining may have on women. The author, however, also indicates that "a growing body of evidence indicates that the increasing women's economic opportunities lead to a higher rate of family savings, greater spending on family nutrition, health and girls' education and declining household poverty" (Tapiero 20102 Inside Mining 13).

But who are the women who are affected by mining? The literature addressing gender and mining issues deals with a wide array of gender issues. Although there may be many more categories, the following women are identified as those involved in or affected by mining: (a) women in management or executive positions; (b) women in administrative or nonartisan positions; (c) women working underground in mines or with hazardous materials; (d) women involved in small-scale mining and (e) women affected by mining (Hope "Dedication to Excellence" 20142 Inside Mining 30-32; Cornish "Transformation Muse" 20142 Inside Mining 33-34; McDonald "Tunnel Vision: Women's Rights Undermined?" Women in mining conference 3 August 2003 (Madang) http://siteresources.worldbank.org/ INTOGMC/Resources/336099.1163605893612/macdonaldtunnelvision.pdf (accessed 2016-02-14)). It seems that it is the last three categories of women that need the most protection from the law.

There are multiple approaches to gender and mining, and multiple issues that one can address from a specific discipline or from an inter-disciplinary

1 The colloquium was organized by Prof Hanri Mostert (UCT) and Ms Fatima Mandhu (University of Zambia) and hosted at ZCAS, Lusaka, Zambia from 21-22 January 2016. The financial support of the National Research Foundation of South Africa is acknowledged with appreciation. The opinions expressed, however, are those of the author. 
approach. One of these approaches could be to establish: (a) the legal framework pertaining to women and mining; (b) to determine the role that women play in mining; or (c) to determine how the law could address the challenges that women face when either affected by mining or being involved in mining. Another approach would be to undertake empirical research and to determine what effects mining has on women. Such a study will necessitate inter-disciplinary team research which is not the purpose of this note. The one approach could, however, not really be divorced from the other as one first has to determine how women are affected by mining and what challenges they experience as a result of mining. One then has to determine which roles they play in relation to mining and then determine the legal framework in relation to mining and gender. Once this is established then it may be considered whether this framework adequately addresses the challenges that women may face. It is immediately acknowledged that gender refers to male and female, and that men and male children may also be affected by mining, but this note will address issues relating to women and mining only.

This note's aim is therefore to provide a general framework pertaining to the different impacts that mining may have on women, based on studies undertaken by other researchers in disciplines other than law, and to indicate the legal frameworks that need to be considered when these impacts are researched. The hope is that it will inspire teams of researchers to undertake further in-depth multi-disciplinary studies to find solutions to this very complex challenge.

This note will address the legal framework to be considered in an African context and will address the different categories of women affected by mining, namely: women working as managers (in executive positions or administrators), women working underground, women affected by mining and finally women in small-scale mining.

\section{Legal framework to be considered in an African context}

As indicated above, cultural and religious barriers are sometimes blamed for not empowering or employing women in the mining sector, or to involve them in decision-making relating to mining in the African context (see also Kloppers and Du Plessis "To be Destitute or to Benefit - Corporate Social Responsibility and Mining in South Africa" in Langton and Longbottom Community Futures, Legal Architecture: Foundations for Indigenous Peoples in the Global Mining Boom (2012) 269 278). At the African Union level 2016 is the "African Year of Human Rights with Particular Focus on the Rights of Women" (see http://www.au.int/en/pressreleases/19615/2016-african-yearhuman-rights-particular-focus-rights-women\#sthash.e2yvfRnP.dpuf

(accessed 2016-01-28)). The Protocol to the African Charter on Human and People Rights on the Rights of Women in Africa (25 February 2005) explicitly places an obligation on member states to "combat all forms of discrimination against women" and to entrench the principle of equality in legislation and in their institutions. Article 2 further prohibits all "discriminatory measures or harmful practices that endanger the health and 
general well-being of women". States are obliged not only to take action in law only but also, as stated, "in fact". Article 3 of the Protocol places an obligation on member states to take measures against the exploitation and degradation of women, where it may impair their human dignity, while article 12 specifically states that women have a right to education and training. Article 13 provides for further protection for women in the workplace. Women should have equal opportunities and should be able to advance their careers, have equal access to employment and equal pay (article 13(a)-(b)). Sexual harassment should be punished and women should be protected in the work place (article 13(c)). There should be minimum age requirements for work and measures against the exploitation of children (article 13(g)). Provision should also be made for maternity leave, amongst others (article 13(i)). A woman's right to health and her productive rights are dealt with in article 14. Article 19 states that women have a right to sustainable development. This right entails, inter alia, that women should have access to and control over productive resources, such as land and their rights to property should be guaranteed. They should further have access to credit, training, skills and their levels of poverty should be reduced (article 19(d)). The negative effects of globalization and implementation of trade and economic policies should further be reduced to a minimum (article 19(e)). The Protocol is therefore clear that all measures that discriminate against women should be addressed. The Protocol, however, also addresses the vulnerability of women towards violence and exploitation and the recognition of their roles as mothers and caregivers (see also Mengesha Reconciling the Need for Advancing Women's Rights in Africa and the Dictates of International Trade Norms: The Position of the Protocol on the Rights of Women in Africa: Focus on the Protocol to the African Charter on Human and Peoples' Rights on the Rights of Women in Africa" 2006 African Human Rights LJ 208-224; 36 states ratified the document, 15 signed the document but have not ratified it yet, and 3 states have not signed nor ratified the document yet, see http://www.achpr.org/instruments/women-protocol/ratifica tion/ (accessed 2016-09-18)).

In the Southern African context similar provisions exist. The South African Protocol on Gender and Development (SADC) (2008, entered into force 22 February 2013) states also that affirmative action should take place, and that barriers should be eliminated that prevent women from participating in all spheres of life (article 5; see also Salgado "Heavy Tread: The Social Footprint of Mines in South Africa: Africa-wide - Monitoring Economies" October 2013 Africa Conflict Monthly Monitor 21-24). "Affirmative action" is defined as "a policy programme or measure that seeks to redress past discrimination through active measures to ensure equal opportunity and positive outcomes in all spheres of life" (article 1). All countries should have introduced legislation in this regard by 2015 (article 6). The multiple roles of women are recognized (article 16), and it is stated that states should ensure women's economic empowerment (article 17). Women should have equal access to employment and benefits, and all forms of occupational segregation and employment discrimination must be eliminated (article 19). The Protocol contains specific provisions relating to gender violence, including sexual harassment, in part six thereof. Article 27 deals with measures pertaining to HIV \& Aids, while article 31 states that women 
should have access to information, technology and information, amongst others, to reach their full potential. The SADC Protocol on Mining (1997, entered into force 10 February 2000), is gender-neutral and does not include any specific measures pertaining to women. The Protocol refers to measures that states have to take in relation to occupational health and safety issues (article 9). Similar to the AU Protocol, the Protocol on Gender and Development clearly prohibits gender discrimination (articles 4 and $6(1)$ ), and affords women protection against violence (articles 6(d), 11(1)(d), 20-25), access to education (articles 11(1)(b) and 14), and places an obligation on states to ensure that women reach their full potential (article 33). All barriers should be removed that could prevent women from enjoying the same privileges as men in the workplace (article 19), while recognizing the multiple roles women play (article 16).

Member states have to consider the African Union Protocols and the protocols of the specific region in which they function, for example, SADC. They have to enact legislation to ensure equal opportunities for women in the workplace, while protecting them from risks that include violence and any practice that may harm, for example, their productive capacity. Although the mines are not directly affected by the Protocols, they may have to consider these protocols as the countries in which they function are parties to the protocols, and individuals may attempt to enforce them either in the national or regional courts (see eg, Fick $v$ Republic of Zimbabwe (SADC (T) 01/2010) [2010] SADCT 8 (16 July 2010); Social and Economic Rights Action Centre (SERAC) v Nigeria (2001) AHRLR 60 (ACHPR 2001); to the SERAC case has been discussed by several authors - read in this regard Nwobike "The African Commission on Human and Peoples' Rights and the Demystification of Second and Third Generation Rights under the African Charter: Social and Economic Rights Action Centre (SERAC) and the Centre for Economic and Social Rights (CESR) v Nigeria" 2005 African Journal of Legal Studies 129-146; Van der Linde and Louw "Considering the Interpretation and Implementation of Article 2 of the African Charter on Human and People's Rights in Light of the SERAC Communication" 2003 African Human Rights LJ 167ff). Mining companies will definitely have to consider the constitution of the particular country where the mine is situated.

In South Africa, section 9 of the Constitution of the Republic of South Africa, 1996 prohibits all forms of discrimination, while section 23 relates to fair labour practices. Section 10 deals with human dignity. Legislation pertaining to the promotion of equality will also have to be considered as the SADC Protocol, for example, expects of their member states to introduce such legislation. In the South African context the Promotion of Equality and Prevention of Unfair Discrimination Act (4 of 2000) and the Employment Equity Act (55 of 1998) will also have to be considered. The mining legislation of the specific country will have to be read to determine whether specific measures are included to deal with gender issues.

In the South African context the Mineral and Petroleum Resources Development Act (28 of 2000) is gender-neutral, but the Mining Charter ("Broad-Based Socio-Economic Empowerment Charter for the South African Mining Industry" 2002) specifically states that $10 \%$ of the workforce must include women. The Mine Health and Safety Act (29 of 1996) (MHSA) was 
also written in neutral terms, and it is only in 2015 that the concerns of women working underground were addressed (see paragraph 32 below). Other legislation that may impact on women working in mining is labour, land, health and environmental legislation. Again in the South African context the labour legislation to be considered is, for example, the Basic Conditions of Employment Act (75 of 1997) and the Labour Relations Act (66 of 1995) that regulate the basic conditions of employment in the workplace, as well as labour relations. Both laws provide equal rights to men and women. The land legislation is known to discriminate against women and not to provide equal access to land also due to past discriminatory practices, as well as due to cultural practices. Although the discriminatory legislation has been repealed, land-tenure reform still has to take place with regard to various permits and rights that were allocated in terms of apartheid legislation, and that have never been normalized (see Pienaar Land Reform (2014) 357-360; Du Plessis and Pienaar "The More things Change, the More they Stay the Same: The Story of Communal Land Tenure in South Africa" 2010 Fundamina 73-90; Claassens and Smythe "Marriage, Land and Custom: What's Law got to do With it?" 2013 Acta Juridica 1-27).

The National Environmental Management Act (62 of 2008) (NEMA) states as a principle that "the vital role of women and youth in environmental management and development must be recognized and their full participation therein promoted" (s 2(4)(q)). In the case of an environmental impact-assessment process the environmental practitioner (with the permission of the Department of Environmental Affairs, or a provincial department), must find alternative methods to ensure persons who cannot participate due to any form of disadvantage participate in the process ( $R$ 54(2)(3) GN R982 in GG 38282 of 2014-12-04). This regulation could be applied to also assist those women who have no voice when mining companies want to establish a mine in their area, but who, due to cultural or religious factors are barred from participating in the process.

It is not only international law and national law that need to be considered. There may also be documents published by international organizations that could be taken into account, or voluntary measures that states or mines could adhere to. The International Finance Corporation and Lonmin published, for example, A Guide to Integrating Women into the Workforce Draft V 1.0 (2009), setting out the "what" and "how" of the integration of women into the mining workforce. Initially the international Underground Work (Women) Convention (45 of 1935) prohibited the employment of women in mines, which exposed them to specific underground-work hazards. The Convention later classified women as "vulnerable workers" with special occupational and safety needs (see eg, ILO Gender Equality and Decent Work (2012); Convention concerning the Revision of the Maternity Protection Convention (Revised) (183 of 2000), read with Recommendation concerning the Revision of the Maternity Protection Recommendation (191 of 2000); Convention concerning Equal Opportunities and Equal Treatment for Men and Women Workers: Workers with Family Responsibilities (156 of 1981), read with Recommendation concerning Equal Opportunities and Equal Treatment for Men and Women Workers: Workers with Family Responsibilities (165 of 1981); Recommendation concerning HIV and AIDS and the World of Work (200 of 2010); Convention concerning 
Indigenous and Tribal Peoples in Independent Countries (169 of 1989); Convention concerning Night Work of Women Employed in Industry (Revised) (89 of 1948); Protocol of 1990 to the Night Work (Women) Convention (Revised), 1948; Convention concerning Night Work (171 of 1990); Recommendation concerning Night Work 178 of 1990; Safety and Health in Mines Convention (176 of 1995)).

South Africa ratified the ILO Safety and Health in Mines Convention (176 of 1995) that "recognizes the desirability to prevent any fatalities, injuries or ill health affecting workers or members of the public, or damage to the environment arising from mining operations" (Preamble). According to article 6 , a mine must take preventive and protective measures and must deal with them in the order of priority as prescribed in the article. In terms of article 6 the employer must:

(a) eliminate the risk;

(b) control the risk at source;

(c) minimize the risk by means that include the design of safe work systems; and

(d) in so far as the risk remains, provide for the use of protective equipment, having regard to what is reasonable, practicable and feasible, and to good practice and the exercise of due diligence.

Although the Convention does not refer to gender, it implies that South Africa has to have measures in place to deal, not only with the safety and health of its workers (including women), but also have to deal with those affected by mining (therefore women), and to address the environmental impacts of mining that affects women. The Convention does not define what would be reasonable, practicable and feasible or good practice, which leave this article open to interpretation of the member states, or if not defined, in the national legislation by way of national standards to the interpretation by the mining companies. It is suggested that states should prescribe, either by way of national standards, or regulation what would constitute good practice in this regard (see also the discussion with regard to protective clothing (paragraph 32 below)).

If different measures are put in place for men and women, some people may regard such measures as discrimination, while others may refer to them as differentiation. The law distinguishes between discrimination and differentiation. Discrimination is never allowed but in certain circumstances differentiation may be allowed (see also Van Marle "The Doubly Prized World - On Transformation, Ethical Feminism, Deconstruction and Justice" 199629 CILSA 329-337). It is sometimes argued that despite all the international documents, protocols, constitutions and legislation proclaiming equality for women, women working in the mining sector (especially underground of working with hazardous materials) should be treated differently from men, and that equal treatment may have to allow for differentiation, in other sectors, where women act in managerial or executive positions, unequal treatment will in most probably be regarded as discrimination. 
In the next section the different categories of women in relation to mining will be discussed.

\section{Categories of women in mining (WIM)}

\section{Women as managers, in executive positions or administrators}

The literature on women in executive positions or working in administrative positions in mining is mostly positive on the role that women play in this regard: "Credit Suisse Research Institute found that companies with women on their boards have a higher return on equity, lower gearing, higher price/book value and better than average growth" (McMaster "Women and Technicians Needed in Mines" 201312 HR Future 26). The Johannesburg Stock Exchange has the best female representation on boards, while the London Stock Exchange has the worst representation (McMaster 201312 HR Future 26). Women managers or administrators complain of issues such as sexual harassment and discrimination (see Saunders and Easteal "The Nature, Pervasiveness and Manifestations of Sexual Harassment in Rural Australia: Does 'Masculinity' of Workplace make a Difference?" 201340 Women's Studies International Forum 121-131; Ozkan and Beckton "The Pathway Forward: Creating Gender Inclusive Leadership in Mining and Resources" (Centre for Women in Politics and Public Leadership Carleton University November 2012) 6). However, the number of women in managerial positions in mines in South Africa has increased significantly (Kweyama "Mining Lekgotla WIM Speech" August 2014 http://southafrica. angloamerican.com/ /media/Files/A/Anglo-American-South-Africa-V2/pre sentation/kk_women-in-mining.pdf (accessed 2016-01-28); Wilhelm "Empowering Women in Mining" 20092 Inside Mining 8:9-11). These women will have to rely on labour legislation to assist them when they have complaints in this regard. The Deloitte Insomnia Index found, however, that legislation does not always support women mine workers whose main tasks are to work underground (McMaster 201312 HR Future 26; Buthelezi "Women Making Inroads into Male-dominated Mining Sector Despite Challenges" 9 August 2013 Mining Weekly http://www.miningweekly.com/ article/exploring-the-leadership-role-of-women-in-the-mining-industry-201308-02 (accessed 2016-01-28)).

The participation of women in the management and boards of mines are also measures in terms of a scorecard on management in control that is included in the Mining Charter and based, amongst others, on the Employment Equity Act 55 of 1998 (see Van den Berg "Broad-based Economic Empowerment" in Badenhorst and Mostert Mineral and Petroleum Law par 23.3.1.2). Mines have to reach set targets in this regard - in the case of women it is 10 per cent (Van den Berg in Badenhorst and Mostert Mineral and Petroleum Law par 23.3.3). 


\section{Women working underground}

It may not necessarily be a woman's first choice to work underground in a mine. According to the literature there are various reasons why women would choose do work underground, for example, that they are unemployed, there is a lack of job opportunities, or that they have limited training or experience to do other jobs (Zungu "Occupational Health and Safety (OH\&S) Challenges Reported by Women in Selected South African Gold and Platinum Mines" 201218 Occupational Health Southern Africa 5:10). The mining industry also pays underground workers fairly well in relation to other types of work that they may qualify for (Calitz Experiences of Women in the Platinum Mining Industry (Unpublished mini-dissertation MA in Industrial Psychology North-West University 2004) 3). In the South African case as indicated above (see paragraph 2 above), the Mining Charter forces mines to employ at least $10 \%$ women as part of their workforce, which opens up job opportunities that women may not previously have had.

Working underground has its challenges. Zungu ("South African Guideline for the Selection and Provision of Personal Protective Equipment for Women in Mining' 201319 Occupational Health Southern Africa 3:4-9; 201218 Occupational Health Southern Africa 5:6-12) did excellent empirical research in this regard, finding that women have "unique safety and health needs resulting from their physiological makeup". According to her "women face equal but different OH\&S challenges at work compared to men ... women suffer most from work-related diseases, including musculo-skeletal and reproductive problems" (Zungu 201218 Occupational Health Southern Africa 5:6-13; 201218 Occupational Health Southern Africa 3:4-9). The different occupational, health and safety challenges that she and other writers (listed at the end of the paragraph) refer to include, amongst others: the type and style of the personal and protective equipment that women must wear - in most instances protective clothing such as the goggles, shoes and hats are designed for men and do not fit women. The overalls are designed for men and their personal needs and do not take women and their personal sanitary needs into account. There are not separate changing rooms for men and women, and the underground toilet facilities are not adequate. There are also complaints about the hygienic conditions of these toilets. There are, for example, no hand-wash facilities. The mines do not provide sanitary bins, causing women to be either too scared to visit the toilets or, not to drink enough liquids to avoid visiting the toilets (Zungu 2012 18 Occupational Health Southern Africa 3:8-9). Owing to the extreme heat conditions underground women develop skin irritations and other gynecological conditions. At some mines, women reported that they are exposed to rape and sexual harassment as well as inhumane treatment by their fellow workers. There are reports of women being murdered underground. Women are scared to work night shifts due to less security. Some mines had to introduce a buddy system where women workers have to work together. This had some cost implications for mines. Pregnant women and women who are nursing may not work underground. This led to resentment as it may result in women receiving pay for more or less 15 months while they cannot do the work they have been trained for. Consequently additional workers have to be hired. Women (similar to men) 
contract diseases, such as HIV \& Aids and tuberculosis as well as other diseases associated with working in mines. Women also feel that they do not have privacy when visiting the mines' health clinics (see with regard to the above paragraph, Kweyama August $2014 \mathrm{http}: / /$ southafrica. angloamerican. $\mathrm{com} / \sim / \mathrm{media} /$ Files/A/Anglo-American-South-Africa-V2/presentation/kk_wom en-in-mining.pdf (accessed 2016-01-28); Saunders and Easteal 201340 Women's Studies International Forum 121-131; Le Roux and Naudé "Communicating with Diversities: Female Employees in the South African Platinum Industry" 200928 Communicare 41-43; Botha and Cronjé "Women in Mining: A Conceptual Framework for Gender Issues in the South African Mining Sector" 201539 South African Journal of Labour Relations 10-37; Botha and Cronjé "Occupational Health and Safety Considerations for Women Employed in Core Mining Positions" 201513 Journal of Human Resource Management http://dx.doi.org/10.4102/sajhrm.v13i1.652; Ntombela 'Women in Mining Face Challenges' 20146 Inside Mining 30-31; Calitz (Unpublished mini-dissertation MA in Industrial Psychology North-West University) 24-36; Senkhane "Mining's Untapped Resource" 20154 Inside Mining 9-11; Govender "A Hard-hitting Reality" 20135 Inside Mining 74-75; Hermanus "Occupational Health and Safety in Mining - Status, New Development, and Concerns" 2008107 Journal of the South African Institute of Mining and Metallurgy 531-538).

There is ample evidence to indicate that women working underground cannot be treated similarly to men. The legislation is clear that there should be no discrimination against women in the workplace, so mines cannot refuse to appoint women doing the work. However, from the empirical studies conducted it seems that there should be a measure of differentiation due to the physical make-up of women. The South African law recognized this differentiation and introduced regulations in this regard in 2015, acting in terms of the MHSA (according to the MHSA, the Chief Inspector of Mines has the duty to determine and implement policies with regard to health and safety at the mines, as well as with regard to people affected by mining (s 49(1)(e)), and may also monitor and control "environmental aspects at mines that affect, or may affect, the health of safety of employees or other persons" (s 49(3)(a)). In this regard he or she must consult with the relevant officer appointed in terms of the Mineral and Petroleum Resources Development Act (28 of 2002) (s 49B makes provision for cooperative governance). The Chief Inspector of Mines issued a Guideline for a Mandatory Code of Practice on the Provision of Personal Protective Equipment (PPE) for Women in the South African Mining Industry in terms of section 49(6) of the Mine Health and Safety Act (29 of 1996) (GN 854 in GG 39228 of 2015-0925 - also referred to as DMR 16/3/2/5-A2).

Once such a Guideline is published the employer of a mine must prepare and implement a code of practice (COP) in accordance with the notice (s 9(2)-(3)). The employer has to consult the mine's health-and-safety committee or a health-and-safety representative (established or appointed in terms of $s$ 25) (s 9(2)). The employer must submit the COP to the Chief Inspector of Mines (s 9(3)). The Chief Inspector may instruct the employer to review the COP if it does not comply with the Guidelines nor adequately protects the health and safety of workers (s 9(9)). A trade union may also request the Chief Inspector to do so (s 9(6)). The employer must identify the 
risks that his or her employers are exposed to, as well as indicate the significance of the risks ( $\mathrm{s}$ 11(1)). The employees have access to these records $(s 11(1)(d))$. The employer must then in consultation with the safetyand-health committees determine the manner in which the risk can be eliminated and controlled at source (s 11(2)). If the risk cannot be controlled, then personal protective equipment has to be provided and a programme instituted to monitor the risks to which the employers are exposed (s $11(2)(d))$. Section 11(3), however, states that the employer "must as far as reasonably practicable implement the measures determined necessary in terms of subsection (2) in the order in which the measures are listed in the paragraphs of that subsection". The mine has to issue personal protective equipment only if all other risks cannot be addressed - it is regarded as the lowest priority in the ranking of risks (see also article 6 the International Labour Organization (ILO) standard and Safety and Health in Mines Convention referred to in paragraph 2 above). "Reasonably practicable" is defined in the MHSA as

"having regard to:

(a) the severity and scope of the hazard or risk concerned;

(b) the state of knowledge reasonably available concerning that hazard or risk and of any means of removing or mitigating that hazard or risk;

(c) the availability and suitability of means to remove or mitigate that hazard or risk; and

(d) the costs and benefits of removing or mitigating that hazard or risk" (s 102).

A "hazard" is regarded as "a source of or exposure to danger" and "risk" as "the likelihood that occupational injury or harm to persons will occur" (s 102). As indicated above, it seems that mines never considered the fact that the exposure of women in mines due to ill-fitting clothes was a "hazard" or "risk" that needed to be addressed. It may also be that the mines in applying what was "reasonably practicable", considered the cost aspect of having to move away from bulk PPE supplies (see eg, Evans, McAlinden and Griffin "Personal Protective Equipment and Dermal Exposure" 200116 Applied Occupational and Environmental Hygiene 334-337), to having to buy redesigned PPE for women. The relevant Guideline of the Chief Inspector of Mines is therefore to be welcomed.

The Guideline does not specifically prescribe which type of PPE the mine should introduce for women, but mines have to consult their safety-andhealth committees or safety-and-health representatives and then draft a COP in accordance with the Guideline. The COP must indicate the mine, its location, the commodities produced, mining methods and process, as well as the systems that the mine used with regard to the issuing of PPE (par 5 GN 854). The COP must also indicate how the significant risks in terms of section 11 of the (MHSA) will be addressed, as well as the hazard identifications and risk assessments that were undertaken; the employer must also ensure that the PPE is suitable for women in mining (par 7-8 GN 854, read with Annexure 3 par 1.6, that describe how a hazard assessment is to be undertaken in relation to women in mining). "Suitable" is defined as "appropriate in terms of size and fit, type of work place hazards, purpose and nature of work to be undertaken and gender anthropometrics" (par 4 GN 
854, read with Annexure 3 that sets out general considerations that have to be taken into account). The COP must also set out the roles and responsibilities of the employer, managers and supervisors as well as women working in mining (par 8). As mines sometimes buy PPE in bulk the effectiveness thereof is not always tested, but paragraph 8.2.5 of GN 854 specifically states that "the use and effectiveness of the PPE is (to be) monitored, including with regard to fit, comfort and maximum protection from the identified hazards for WIM" (women in mining) (the hazards are set out in Annexure 2 to GN 854). Women will have to undergo training in the use and maintenance of the new PPE.

Although GN 854 is to be welcomed as it addresses one of the major issues that women experience when they work underground, namely PPE, but it still does not address issues such as separate toilet facilities and changing rooms, sanitary bins, safety issues relating to heavy equipment, rape and murder, violence and sexual harassment. The MHSA is very clear in this regard and places an obligation on the Inspector of Mines and the mines to see to the safety and health of all their workers - these are issues that also need urgent attention, and where innovative measures will most probably be reasonably practicable to implement without excessive costs to the mine.

\section{Women in surrounding areas of mines}

Mines are mostly located in rural areas where the stakeholders of the community have to be consulted. The identification of stakeholders is an important part of the premining-consultation process. The community has to be consulted, and the Department of Mineral Resources has to take their views into account (Bengwenyama Minerals (Pty) Ltd $v$ Genorah Resources (Pty) Ltd 2011 (4) SA 113 (CC); 2011 (3) BCLR 229 (CC) (30 November 2010); for a discussion of the case, see Badenhorst and Olivier "Host Communities and Competing Applications for Prospecting Rights in Terms of the Mineral and Petroleum Resources Development Act 28 of 2002" 2011 De Jure 9ff; Badenhorst, Olivier and Williams "The Final Judgment" 2012 TSAR 106-129; Humby "The Bengwenyama Trilogy: Constitutional Rights and the Fight for Prospecting on Community Land" 201215 PER 166-188; see also Murombo "Law and the Indigenisation of Mineral Resources in Zimbabwe: Any Equity for Local Communities?" 201025 Southern African Public Law 568-589; Salgado 2013 Africa Conflict Monthly Monitor 21-24).

Disputes usually arise as to who the stakeholders are. In a traditional community mines sometimes consult the traditional leader and his council and not necessarily the community as such. In a community without a traditional leader negotiations are conducted with men, while women are not necessarily included as their role is seen as the caretaker of the family and not the decision-maker. This result in women having no say in whether a mine is placed in their vicinity, whether they have to be relocated from their ancestral land, or whether their land is most probably going to be polluted by mining activities (see also the several case studies done by the Bench Marks Foundation http://www.bench-marks.org.za/ (accessed 2016-01-31 (page references))). As indicated above, some women still have no access to land or rights in land, nor the means to exploit the land. Without any say in 
the placement of a mine or how the mine is going to influence their lives, women are left in the lurch (see also Munyinda and Habasonda "Public Participation in Zambia The Case of Natural Resource Management" 2013 http://menneskeret.dk/files/media/dokumenter/udgivelser/public_participation study_final-nov2013.pdf (accessed 2016-01-31); Walker "Land Reform in Southern and Eastern Africa: Key Issues for Strengthening Women's Access to and Rights in Land" (Food and Agricultural Organization Report 2002)). It seems that more notice is currently being given to communities and their protests, as the Department of Mineral Resources published a notice of intent to place an 18-month moratorium on prospecting and mining in the Xolobeni area in the Eastern Cape (GN 1014 in GG 40277 of 2016-09-15).

In South Africa women are those who have to till the fields, to ensure food security for their families and who are left in the rural areas to look after the children, while men are working either on the mines or in the cities. They are affected by the mining activities and should be consulted (Hamann "Mining Companies' Role in Sustainable Development: The 'Why' and 'How' of Corporate Social Responsibility from a Business Perspective" 200320 Development Southern Africa DOl:10.1080/03768350302957). The environmental impact-assessment regulations (GN R982 in GG 38282 of 2014-12-04) are clear that all interested and affected parties should be identified and, as stated above, section 2 of NEMA states that women should be consulted. Mining companies ignoring women could be taken to court for not properly consulting with all the stakeholders in the community.

People living in the vicinity of mines are exposed to certain illnesses, not only HIV \& Aids, but also Tuberculosis (TB) and sexually transmitted infections (STIs), silicosis and asbestosis (Hurkchand et al "Measuring the Impact of HIV and STIs in a Community in a Coal Mining Town, Mpumalanga, South Africa" 2005105 The Journal of the South African Institute of Mining and Metallurgy 365-368; Cornoa and De Walqueb "Mines, Migration and HIV/AIDS in Southern Africa" 201222 Journal of African Economies doi: 10.1093/jae/ejs005). Women also have not always had the same access to health benefits. Pre-1975 women who worked "cobbing asbestos ore" on mines in South Africa, for example, who left the mines after it became illegal for them to work there, had not been compensated nor treated when they left the mines. They had to live with the disease while the men in the community could access the health services of the mines while they were in the employ of the mines (Davies et al "Asbestos-related Lung Disease Among Women in the Northern Province of South Africa" 200197 South African Journal of Science 87-111).

Women have to bear the brunt of water pollution, for example. In some areas they now have to walk further to access "clean" water for cooking, washing and their daily needs (Oxfam Women, Communities and Mining: The Gender Impacts of Mining and the Role of Gender Impact Assessment (2009) 7). These impacts multiply when women participate in small-scale mining. 


\section{Women and small-scale mining}

Small-scale mining is on the increase. There are more and more women and children involved in small-scale mining in Africa, and most of these practices are not regulated. The women are not paid well and there is no regulation of occupational and health issues. The women working in these mines are exposed to chemicals and all kinds of other dangers (Spiegel "Socioeconomic Dimensions of Mercury Pollution Abatement: Engaging Artisanal Mining Communities in Sub-Saharan Africa" 200968 Ecological Economics 3072-3083). There are also many deaths associated with small-scale mining (ILO "Social and Labour Issues in Small-scale Mines" ILO/99/10). However, small scale mining may have a positive effect too, when not only the global companies benefit but also the communities on the ground. In order to ensure that the communities or women involved in small-scale mining actually benefit, regulation and legislation would be necessary. It is, nevertheless, also reported that small-scale miners do not always want to be regulated and prefer to work outside the legal framework (Hinton, Veiga and Beinhoff "Women and Artisanal Mining: Gender Roles and the Road Ahead" in Hilson (ed) Socio-economic Impacts of Small-scale Mining in Developing Countries (Swets Netherlands 2003) Chapter 11). Regulation of small-scale mining and the protection of workers, especially women, still needs urgent attention.

\section{Conclusion}

The international, regional and national laws are clear that discrimination is not allowed and that women should be allowed to play a role in mining. There should be no discrimination against women working in executive, managerial or administrative positions. Women are to be regarded as equal partners. In reality, however, it seems that there may be a need for differentiation when women miners work underground or in small-scale mining enterprises, as well as that their specific occupational, health and safety needs should be taken into account. The South African Government set an example by issuing PPE regulations forcing the mines to comply in future. Mines will, in addition, have to address the protection of women against sexual harassment, rape, murder and inhumane treatment by fellowworkers by introducing proper security, education and training.

Mines should be conscious of including women in public-participation processes prior to mining, and to break the cultural and religious barriers that may prevent them from participating. There are ways and means of addressing these issues during a public-participation process (see eg, Department of Environmental Affairs "Public Participation Guideline" GN 807 in GG 35769 of 2012-10-10). Women should have a say in matters that may affect their access to land, credit, water and food security.

It is of the utmost importance that States address small-scale mining and the occupational-and-health effects thereof. It is the women and children that carry the brunt of small-scale mining. More research will be necessary and multidisciplinary teams need to address the issues of women in mining - but these teams will need to involve legal experts as international, regional and 
national laws will have to be taken into account. In the year 2016, where it is the Year of Women's Rights in Africa, it may a good idea to bring all the issues impacting on women's rights, also in relation to mining, to the table and to ensure that governments and the private sector address these issues. Africa is built on women - let women reap the benefits of mining while the mining companies bear the risks.

Willemien du Plessis North West University, Potchefstroom 